\title{
Perspective on Polio Eradication - What is the Issue?
}

\author{
Sultan Mustafa, ${ }^{1,2, *}$, Summaya Ghazal ${ }^{2}$, Sumbal Waheed ${ }^{2}$ \\ ${ }^{1}$ Department of Pediatrics, Karachi Medical and Dental College, Karachi, Pakistan. \\ ${ }^{2}$ Department of Pediatrics, Abbasi Shaheed Hospital, Karachi, Pakistan.
}

\begin{abstract}
WHO proclaims polio a social and community health crisis. Global Polio Eradication Initiative (GPEI) was resolved to make world polio-free and had contributed significantly to eradicate polio from 1000 cases per day in 1988 to 8 per year in 2017 [1, 2]. However, this disease is still widespread in Afghanistan and Pakistan, due to number of problems, an important topics for debate, which poses great threat to the re-emergence of the deadly disease worldwide. Yet, these two countries potential risk should not be taken lightly, as in the seam of 2002 to 2005, reinvigoration and re- entry of polio occurred in 21 countries, with the increase in global migration of people [3]. Till August 13th 2018, 17 WPV1 cases have been reported (thirteen in Afghanistan and four in Pakistan), compared with 22 cases in endemic countries reported in 2017, and its transmission is still continue in Pakistan, as being isolating from the wastewater samples [4]. Therefore, Utmost suggestions are made to improve the status of polio from the remaining two countries as well, by approaching to it through new different strategies and ideas focusing current experiences and issues to eradicate polio as soon as possible.
\end{abstract}

Keywords: Global polio eradication initiative (GPEI), Polio- free, Wild polio virus 1 (WPV1), Reinvigoration, Re- entry, Wastewater samples.

\section{INTRODUCTION}

Poliomyelitis, derived from Greek words polios (grey), muelos (matter), itis (inflammation), is a disease that affects the human or animal tissue by invasion in to the central nervous system by the polio virus type 1, 2 and 3 and the major route of polio transmission is feco-oral, which spread can be control.

Eradication of smallpox in May, 8, 1980, served as the foundation for polio eradication and thus in 1988, the World Health Assembly agreed to wipe out poliomyelitis globally by 2000, and remarkable advances had been made. To achieve this goal, the WHO used 4 key approaches: routine immunization with somewhat four oral polio vaccine doses, National Immunization Days, acute flaccid paralysis surveillance and door-to-door OPV "mop-up" immunization accomplished in a limited geographical region [5]. However, despite all the efforts, WPV is still endemic in two countries, Afghanistan and Pakistan; where in Pakistan circulating vaccine-derived poliovirus type 2 (cVDPV2) is also being reported [6]. Nigeria is now declared polio-free country [7]. The reason to fail to eradicate in both countries are many, both at national and international levels and many action plans have been initiated to control the spread of polio and works on its eradication. Like in November 2012, the Polio Eradication and Endgame Strategic Plan for 2013-2018 were established, attempting to make the disease history by constructing a polio-free world. But the targets of the GPEI Endgame plan to break the chain of wild-type poliovirus transmission by the end of 2014 were

*Address correspondence to this author at the Department of Pediatrics, Karachi Medical and Dental College, Karachi, Pakistan.

E-mail: kmdcash@hotmail.com not fulfilled [8].

All in all, polio is restrained from almost the entire world; however, it remains an immense dilemma in Pakistan. This paper will figure out the issues challenged by Pakistan in their battle against polio and the many logics behind. Suggestions will be made based on the peculiar surveys performed in this ground, for the hurdles faced by Pakistan.

\section{ISSUES IN THE FAILURE OF POLIOMYELITIS ERADICATION IN PAKISTAN}

Among all hurdles, three main were studied in 2016 included refusal of vaccination by the parents, security issues for polio workers and concerns regarding vaccines safety and efficacy. There is no doubt that the government authorities have the prime responsibility in polio eradication. Likewise, as deficiencies in political advocacy, there were also political factors responsible for the inadequacy of polio elimination in Pakistan. This can be illustrated by a fictitious vaccination operation organized by the CIA in the search for Osama bin Laden in 2011, which cause a big polio outbreak in Pakistan between 2014-2017, giving a collateral damage to the country $[8,9]$. To overcome this issue, Prime Minister of Pakistan approved the National Emergency Action Plan for Polio Eradication in 2015 [10]. This example emphasize the fact that in the last steps of elimination constant advocacy at the supreme political level is needed to keep the momentum of the program; any flaws in this area may postponed in acquiring early targets.

Moreover, most identified major issue in the failure was refusal of child to be vaccinated by the families. Families in 
FATA and KPK province have religious beliefs that these vaccines are anti-Islamic and this is compounded by their local religious leaders who belief that these vaccine cause sterility and death. For these reasons, $90 \%$ cases of polio were identified in these two provinces [11]. Lack of success in participation and poor leadership are major factors that have put-up wild polio virus still an endemic problem in these two countries [12]. Public transportation need to be look thoroughly as it is also as important as other elements of failure, large scale social transformation, as in cultural reforms needed [11].

Most importantly, Polio workers wants through their untiring efforts to safe and ensure each individual of less than ten years who coming from endemic area leaves poliovirus behind but, their security and financial support was not guaranteed, which put negative impact and fatigue in their efforts and that contribute to failure in the immunization program $[13,14]$. A study conducted in Pakistan from 2007 to 2014 represented that there were 645 paralytic polio cases reported in the Khyber Pakhtunkhwa Province and the Federally Administered Tribal Areas, secondary to extreme levels of insecurity from extremist groups in northwest Pakistan. In this campaigns, the workers and vaccine utilizers were threatened, which lowered rates of vaccination to inaccessible young one. Hence, there is a strong inverse relationship between polio immunization rates and paralytic polio case rates [15].

The efficacies of polio have been questioned after emergence of polio in completely vaccinated children in India [10]. Every time in National Immunization Day, more than $90 \%$ coverage had been reported, so it is not practically possible that a vaccine that is efficacious in one area fails to achieve same potency in another area. Therefore, close observation and examination of each steps of vaccine is needed, to determine whether continuing outbreaks are due to failure to vaccinate or vaccine failure in these regions. Cities like Karachi have areas of slums as well as peoples from Baluchistan and Northern Pakistan are prone to decreased immunization coverage [16]. Failure to provide good vaccination coverage to this group leads to delays in polio eradication. In the midst of all these barriers, gender issues have also raised the concerns. This especially occurs when an all-male vaccinator team arrives at a home where a female is alone with her kids and the elders of community have not allowed the entrance of males at home resultant hindrance in polio vaccination. Also, Pakistan is a male dominant country where even if a mother is willing to get her child vaccinated and the father disagrees then that child will not get vaccinated unfortunately [17]. To achieve and maintain the eradication, weakest links should be addressed, including providing high vaccination coverage to aforementioned areas, to insecure areas and also to individuals with poor health like immunocompromised patients who continue to excrete vaccine derived virus for prolong period of time [13]. Low literacy levels, high poverty should also address. Therefore, to attain global polio eradication endgame in future, regular immunization coverage, monitoring of vaccine quality and maintaining its cold chain, AFP surveillance and timely investigations are prudent [18].

Another important issue is funding gap. The initial estimate for polio eradication was US\$2 billion which has crossed to much high levels of US\$ 7 billion until 2020.the partners working with the GPEI pledge with financial support needed to finally eradicate polio but it still lack a US\$ 300 million from US\$ 7 billion, which could be long term challenge for fund-raising and may threaten the whole eradication efforts again, as happened in 1999 and 2003 [19, 20]. Multiple private sectors have accelerated the initiative, especially Rotary International in the form of independent funds and giving number of volunteers. Additional private sector support has come from industrialist which paid for media broadcasting, provided transport, purchased local goods and provided food for vaccinators in the ground. They circulate individually political liberty and available means in both polio- prevalent and polio- free countries [21]. Moreover, specific to Pakistan, health infrastructure should be reinforced. The quantity of fixed EPI units should be increased, basically in rural areas, for effective service provision in difficult-to-reach areas of the country, for which fixed financial support required to achieve a step towards polio eradication in the country. District health officials should be completely trained and assessed to make sure that coverage is adequate [22].

As paralytic poliomyelitis were reported in Namibia in early 2006, among 14- 51 years old people, where nineteen cases were confirmed after virus isolation of which wild poliovirus type 1 and 26 were classified as polio compatible. Eleven deaths occurred among them $[23,24]$. So, the general public of 2006 circulates a myth that immunizing all children will prevent only childhood polio; adults are not safe still, resulting in low participation and poor cooperation $[9,25]$.

Now, at the border of polio eradication world face new threats and challenges after encountering confirm cases reported of circulating vaccine derived polio virus2 (cVDPV 2 ) in poliofree countries, which was initially considering as the cause of polio importation from endemic countries [26]. Pakistan being a developing country still faces problems of frequent power failures and shortage of proper technical equipment needed for vaccine storage thus interfering the cold chain of polio vaccine leaving it less efficacious. This might have led to emergence of vaccine derived polio viruses (VDPV) and vaccine associated paralytic polio (VAPP) [27]. To control the issue, Endgame Strategic Plan was revised and goaled to complete eradication contamination of all wild vaccine-related Sabin provinces to reach Herd Immunity so 
that no child ever again suffer from paralytic polio [28].

\section{CONCLUSION}

Polio is almost near to the end of eradication. The only willpower needed is commitment with the cause- at all levels, from parents' willingness to government persistent support and effort. Only then, we will be able to accomplish our goal of removing this dreadful paralytic problem from the world.

Currently, attention to emerging threats is needed with urgent counteractive measures, so that the current slow progress can be speed up. Though, Pakistan peace has been established, war for terrorism has been accomplished. Now it's time for solely focused new action plans to work with heart and soul to achieve the targets and make Pakistan also one of the poliofree country.

It is bright-line that one day the world will be able to eradicate polio, though significant effort still to be needed.

\section{CONFLICT OF INTEREST}

Declared none.

\section{ACKNOWLEDGEMENTS}

Declared none.

\section{REFERENCES}

[1] Hull HF, Ward NA, Hull BP, Milstein JB, deQuadros CA. Paralytic polio: Seasoning strategies, disappearing disease. Lancet 1994; 343: 1331-7. DOI: 10.1016/S0140-6736(94)92472-4

[2] Pakistan: Polio Outbreak - 2014-2017. 2018; Available at: https://www.humanitarianresponse.info/en/disaster/ep-2014-000165-pak

[3] WHO. Resurgence of wild poliovirus type 1 transmission and effect of importation into polio free countries, 2002-2005. Wkly Epidemiol Rec 2006; 81: 63-8.

[4] Khan F, Datta SB, Quddus A, et al. Progress toward polio eradication - worldwide, January 2016-March 2018. MMWR Morb Mortal Wkly Rep 2018; 67(18): 524-8. DOI: $10.15585 / \mathrm{mmwr} . \mathrm{mm} 6718 \mathrm{a} 4$

[5] Abzug MJ. Nonpolio enteroviruses. Kliegman RM, Stanton BMD, Geme J St, Schor NF Eds. Nelson Textbook of Pediatrics. $20^{\text {th }}$ ed. USA: Elsevier 2015; p. 1561.

[6] WHO. Pakistan - GPEI - Global polio eradication initiative. 2016; Available at: http://polioeradication.org/where-we-work/pakistan/

[7] WHO. Nigeria declared polio free, removed from endemic list. 2015; Available at: http://www.rotary.org/eng/Nigeria-declared-polio-free-removed-endemic-list
[8] Nadeem NJ. The global polio eradication initiative (GPEI) in Pakistan. J Pak Med Assoc 2016; 66(11): 1466-71.

[9] Rohra DK. Failure of polio eradication in conflict areas: Another perspective. BMJ 2014; 348: g3124.

[10] Abimbola S, Malik AU, Mansoor GF. The final push for polio eradication: Addressing the challenge of violence in Afghanistan, Pakistan, and Nigeria. PloS Med 2013; 10(10): e1001529. DOI: 10.1371/journal.pmed.1001529

[11] John TJ, Shah NK, Thacker N. Indian academy of pediatrics and polio eradication in India. Indian Pediatr 2006; 43: 765-8.

[12] Dowdle WR. The principles of disease elimination and eradication. MMWR Morb Mortal Wkly Rep 1999; 48: 23-7.

[13] Endpolio Pakistan. Killing of polio workers and security personnel is deplorable. 2015; Available at: http://www.endpolio.com.pk/media-room/media-releases/227-killing-of-polio-workers-and-security-personnel-is-deplorable

[14] Verma AA, Jimenez MP, Tangermann RH, Subramanian SV, Razak F. Insecurity, polio vaccination rates, and polio incidence in northwest. Proc Natl Acad Sci USA 2018; 115(7): 1593-8. DOI: $10.1073 /$ pnas. 1711923115

[15] Gulland A. WHO workers are shot at during vaccination campaign in Pakistan. BMJ 2012; 345: e4951. DOI: 10.1136/bmj.e4951

[16] O'Reilly KM, Durry E, ul Islam O, et al.The effect of mass immunisation campaigns and new oral poliovirus vaccines on the incidence of poliomyelitis in Pakistan and Afghanistan, 2001-11: A retrospective analysis. Lancet 2012; 380(9840): 491-8. DOI: 10.1016/S0140-6736(12)60648-5

[17] Global Polio Eradication Initiative. Gender and Polio. 2018; available at http://polioeradication.org/gender-and-polio/gender-and-polio-eradication/

[18 Thompson KM, Duintjer Tebbens RJ. Lessons from the polio endgame: Overcoming the failure to vaccinate and the role of subpopulations in maintaining transmission. J Infect Dis 2017; 216(Suppl-1): S176-82. DOI: 10.1093/infdis/jix108

[19] Thacker N, Shendurniker N. Current status of polio eradication and future prospects. Indian J Pediatr 2004; 71: 241-5. DOI: $10.1007 / \mathrm{BF} 02724277$

[20] Global Polio Eradication Initiative. Annual expenditures and forecasts 1988-2008. Geneva: WHO 2007; Funding update [online]. Available at: http://www.polioeradication.org/content/general/FRR_07Jan_AnnualExpenditure.pdf

[21] GPEI. Current contributions and pledges, 2013-2020. 2017; Available at: http://www.polioeradication.org/financing/donors/current contributors/

[22] Hussain SF, Boyle P, Patel P, Sullivan R. Eradicating polio in 
Pakistan: An analysis of the challenges and solutions to this security and health issue. Global Health 2016; 12: 63.

DOI: $10.1186 / \mathrm{s} 12992-016-0195-3$

[23] CDC. Perspectives from the global poliomyelitis eradication initiative. 2015; Available at: http://www.cdc.gov $>$ Mmwr $>$ mmwrhtml

[24] Yusuf N, de Wee R, Foster N, et al. Outbreak of type 1 wild poliovirus infection in adults, Namibia, 2006. J Infect Dis 2014; 210 (Supple 1): S353-60. DOI: 10.1093/infdis/jiu069

[25] Global Polio Eradication Initiative. Monthly situation reports [online]. Geneva: WHO 2006; Available at: http://www.polio- eradication.org/content/general/current_monthly_sitrep.asp

[26] Global Polio Eradication Initiative. Stopping polio at the border. 2018; Available at: http://polioeradication.org/news-post/stopping-polio-at-the-border/

[27] Khan MT, Zaheer S, Shafique K. Maternal education, empowerment, economic status and child polio. BMJ Open 2017; 7(3): e013853. DOI: 10.1136/bmjopen-2016-013853

[28] Global Polio Eradication Initiative. Polio-eradication and endgame strategic plan 2013-2018. 2018; Available at: h t t p :// polioeradication.org/wp-content/uploads/2016/07/PEESP_EN_A4.pdf

Received: September 17, 2018

Accepted: January 23, 2019

(C) 2019 National Journal of Health Sciences.

This is an open-access article. 